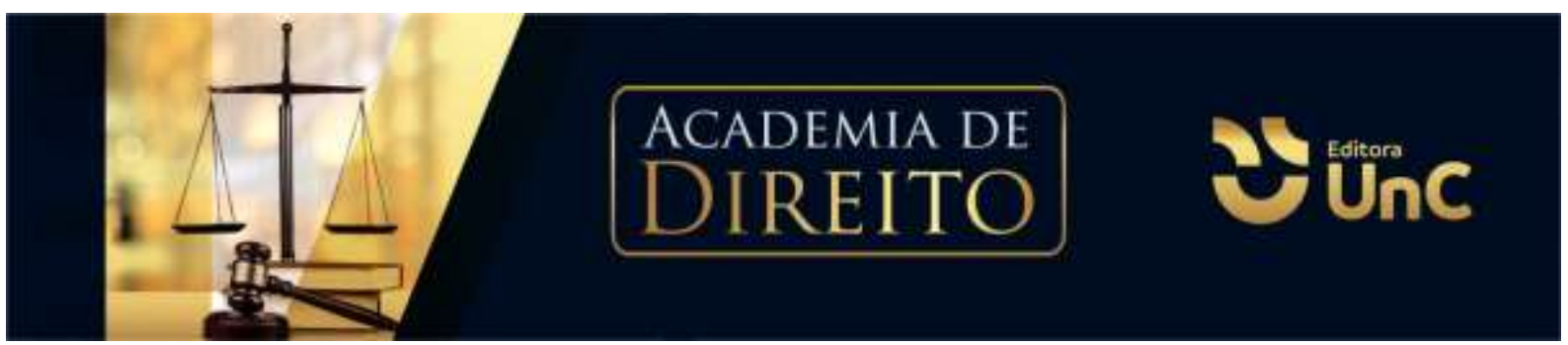

\title{
CONTRADITÓRIO SUBSTANCIAL E O PRINCÍPIO DA VEDAÇÃO À DECISÃO SURPRESA NO PROCESSO CIVIL
}

\section{Substantial contradictory and the principle of the prohibition of surprise decision in the civil process}

Ismael Júnio Masson ${ }^{1}$ Jandir Ademar Schmidt ${ }^{2}$

\begin{abstract}
RESUMO
O Código de Processo Civil de 2015 trouxe diversas inovações, dentre elas a positivação de alguns princípios. Como base deste estudo os princípios do contraditório e da vedação à decisão surpresa serão analisados, tendo como objetivo principal responder o seguinte questionamento: qual a relação e a aplicabilidade entre o princípio do contraditório e a vedação à decisão surpresa? Para tanto foram estudados os conceitos e características, bem como demonstrada a relação e aplicabilidade de ambos os princípios dentro do Código de Processo Civil e na jurisprudência do Tribunal de Justiça de Santa Catarina. A metodologia utilizada foi por meio da abordagem dedutiva, aplicando a técnica de pesquisa bibliográfica, jurisprudencial e documental, a partir de revisão doutrinária e busca em artigos científicos, bem como, a análise sobre a legislação brasileira. Com isso, pode-se concluir que para tutelar de forma adequada o direito, o contraditório precisa ser efetivo, sendo que até questões de ordem pública devem ser levadas às partes para que seja viabilizada a comunicação entre os sujeitos do processo, e exercido o poder de influência nos pronunciamentos do Judiciário, de forma a impedir a prolação de decisões que surpreendam as partes.
\end{abstract}

Palavras-Chave: Princípios. Contraditório. Decisão. Surpresa. Código.

\begin{abstract}
The Civil Procedure Code of 2015 has brought several innovations. One of them is the materialization of some principles into positive legislation. This present research will focus on the principles of the contradictory and the prohibition of surprise decision with the main objective of answering the following question: what is the relationship and applicability between the principle of the contradictory and the prohibition of surprise

\footnotetext{
${ }^{1}$ Acadêmico do Curso de Graduação em Direito da Universidade do Contestado. Campus Concórdia. Santa Catarina. Brasil. E-mail: ismaelmasson18@gmail.com

${ }^{2}$ Mestre em Direito pela Universidade Federal Santa Catarina e Professor do Curso de Direito da Universidade do Contestado - Campus Concórdia. Santa Catarina. Brasil. E-mail: jandir.schmidt@gmail.com
} 
decision? To that end, both concepts and characteristics of these principles were analysed, as well as the relationship and applicability of both principles within the Civil Procedure Code. The methodology applied in this research was based on deductive approach, bibliographic techniques, jurisprudential and documentary research, as well as doctrinal reviews, published scientific articles and the analysis of Brazilian legislation. After due ponderation, it became evident that in order to adequately protect the law, the contradictory must be effective even when regarding issues of public order. In such cases, the parties must be brought together so that the communication between the subjects of the process of law is made possible and through the power of influence exercised over the pronouncements made by the Judiciary, avoid decisions that can surprise the parties involved.

Keywords: Principles. Contradictory. Decision. Surprise. Code.

\section{INTRODUÇÃO}

Os princípios constituem o fundamento das regras positivadas no ordenamento jurídico brasileiro, são a base e o limite de criação e aplicação do direito. Pode-se afirmar que além do papel normativo que os princípios possuem, outra função precípua é do preenchimento de lacunas deixadas pela legislação, devendo o judiciário, ao se deparar com omissão normativa, aplicar tais fundamentos.

O processo civil no Brasil sofreu recente alteração com a Lei n. 13.105/2015, trazendo grandes inovações. Dentre as diversas alterações trazidas pelo Código, encontra-se a positivação de alguns princípios processuais de suma importância, tendo como destaque neste estudo o princípio da vedação de decisão surpresa e do contraditório.

Nesse ponto, merece destaque o fato de que por muitas vezes o Judiciário prolata decisões que dão fim ao litígio sem antes oportunizar às partes manifestação acerca do tema levantado, o que torna o processo moroso, já que as partes terão que discutir em sede recursal questão que poderia ter sua resolução no primeiro grau de jurisdição, se lhes houvessem sido oportunizado o contraditório ulterior à decisão.

Como será aprofundado, os princípios do contraditório e da vedação à decisão surpresa estão intimamente ligados. O exercício de um contraditório pleno viabilizará que seja oportunizada às partes manifestação sobre a matéria em discussão - ainda que seja de ordem pública - para que estas sejam mais do que apenas cientificadas, mas possam influir nas decisões prolatadas ao longo do processo. 
Previsto na Constituição Federal, a garantia do contraditório possui relação estreita com o princípio de vedação à decisão surpresa. Neste estudo serão abordados os conceitos e características destes princípios, bem como o poder de influência que as partes exercerão sobre a decisão do magistrado, a fim de evitar a prolação de decisões que surpreendam as partes.

Em virtude de tudo isso, o presente estudo visa a resposta ao questionamento acerca da relação e aplicabilidade dos princípios do contraditório e a vedação à decisão surpresa.

Para a realização da pesquisa e elaboração do presente artigo, foi utilizado o método de abordagem dedutivo, aplicando a técnica de pesquisa bibliográfica, documental e jurisprudencial, a partir de revisão doutrinária e busca em artigos científicos, bem como, a análise sobre a legislação brasileira.

Tem-se como objetivo principal apontar a relação entre o contraditório e a vedação à decisão surpresa. Para tanto serão estudados os conceitos e características, bem como demonstrado o ponto de encontro entre ambos princípios.

Nesse diapasão, torna-se relevante o estudo do tema em comento diante da indispensabilidade destes princípios às partes dentro do processo judicial.

\section{PRINCÍPIO DO CONTRADITÓRIO}

O direito brasileiro é constituído por um ordenamento jurídico, havendo hierarquia entre as normas existentes, sendo considerada a Constituição Federal a Lei Maior, a qual se sobrepõe as demais. Entretanto, o direito não deriva apenas da legislação positivada, mas também de outras fontes, sendo que, dentre outras, merecem destaque os princípios, os quais devem embasar a criação e aplicação da Lei.

Derivado do princípio do devido processo legal, o princípio do contraditório, tema em enfoque, possui previsão Constitucional, assumindo grande relevância dentre os fundamentos do direito brasileiro, já que proporciona a chamada condução dialética do processo, cabendo direito de defesa entre as partes em relação aos atos produzidos, podendo estas se oporem, dar versão que lhe seja favorável, ou, ainda dar interpretação diversa aos fatos e fundamentos utilizadas pela outra parte (MORAES, 2003). 
Desde os primórdios foi identificada a necessidade de ouvir a quem está sendo julgado. Dentro do direito romano o contraditório foi classificado como o direito de informação e reação da parte dentro do processo. Neste contexto, as partes possuem o direito de serem informadas de eventuais decisões que serão prejudiciais a elas (CABRAL, 2010), o que remete ao princípio da vedação à decisão surpresa, tema que será abordado posteriormente.

Com o passar do tempo, identificou-se a necessidade de ampliar o contraditório concedido às partes prejudicadas. Tal pensamento fora adotado pelo direito Germânico, sendo considerada uma interpretação mais democrática, desviando de uma análise tradicional do princípio em questão (CABRAL, 2010).

Acerca do devido processo legal, tal princípio teve sua origem na Constituição de Charta Libertatum, de 1215, bem como na Declaração Universal dos Direitos do Homem, em 1948, a qual garantiu aos acusados o direito de haver um julgamento antes de serem considerados culpados, no qual deveriam ser assegurados seus direitos de defesa, sendo que o contraditório é uma consequência da aplicação do princípio do devido processo legal (MORAES, 2003).

Com relação à previsão legal dentro do direito brasileiro, o princípio do contraditório encontra-se positivado tanto na norma Constitucional como na infraconstitucional.

A Constituição Federal de 1988 é conhecida por ser uma norma garantista, não sendo diferente com relação ao contraditório, preceituando em seu artigo $5^{\circ}$, inciso LV: "aos litigantes, em processo judicial ou administrativo, e aos acusados em geral são assegurados o contraditório e ampla defesa, com os meios e recursos a ela inerentes" (BRASIL, 1988).

Antes da atual Constituição, tal princípio abrangia unicamente a esfera penal, "entrementes, antes mesmo da promulgação da Carta Política vigente, parte da doutrina já apontava a extensão do direito ao contraditório a processos de natureza administrativa e civil" (SANTOS JUNIOR, 2013).

No âmbito do processo civil, em que pese outros códigos já terem positivado tal princípio, o Código de Processo Civil de 2015 o positivou em seu artigo $7^{\circ}$ determinando que: "É assegurada às partes paridade de tratamento em relação ao exercício de direitos e faculdades processuais, aos meios de defesa, aos ônus, aos 
deveres e à aplicação de sanções processuais, competindo ao juiz zelar pelo efetivo contraditório."

Da leitura dos referidos artigos, denota-se que, além de ser um dos princípios de maior destaque dentro do direito brasileiro, o princípio do contraditório possui sua expressa previsão dentro do Ordenamento Jurídico, sendo indiscutível a sua importância dentro de qualquer litígio, seja administrativo ou judicial.

É inegável a relevância ao direito brasileiro do princípio estudado. Por outro lado, não se pode ignorar que, apesar de essencial, tal direito não é absoluto, havendo limites à sua atuação quando contrapostos a outros princípios fundamentais. Acerca do tema Santos (2018) leciona que existem três limitações ao contraditório, elencadas em: contraditório inútil, contraditório postecipado e contraditório eventual.

A primeira limitação abrange a ideia de que, por vezes, o contraditório é inútil. Essa inutilidade se dará quando a decisão tomada em cognição sumária seja a favor da outra parte, sendo desnecessário o contraditório nestes casos. Isso ocorrerá nos casos de indeferimento da petição inicial, improcedência liminar do pedido e decadência ou prescrição da pretensão, nos quais não havendo prejuízo à parte não ouvida, o magistrado não será obrigado a oportunizar o contraditório ao réu, já que a decisão será em seu favor.

Já o contraditório postecipado ocorrerá quando o juiz postergar a resposta da outra parte para momento posterior à decisão judicial que a desfavoreça. Salienta-se que o contraditório não deixará de ser respeitado, apenas será adiado. Assim, nesta hipótese o juiz decidirá sem a oitiva da parte contrária em razão da urgência do caso, da evidência do direito, ou ainda no procedimento de ação monitória.

Por fim, a última hipótese de limitação ao princípio do contraditório (eventual) ocorrerá nas ações de execução e nos casos de ações para estabilização da tutela antecipada antecedente. Tem-se que a eventualidade se dá, nas ações de execução, em virtude de que o executado é intimado para cumprir sua obrigação, e não para manifestar-se, sendo que apenas terá direito à manifestação nos casos elencados em Lei. Em relação às ações para estabilização da tutela antecipada antecedente, o contraditório torna-se eventual 
após a extinção do processo, com a estabilização dos efeitos da tutela antecipada concedida [...] a depender da propositura de demanda pelo réu da demanda anterior com a finalidade de rever, reformar ou invalidar a tutela antecipada estabilizada (SANTOS, 2018).

Nas palavras de Nelson Nery Junior (2010): "o afastamento pontual do contraditório [...] é não só admitido, como também recomendável [...] à luz de outros princípios e valores buscados pelo processo moderno.

Entretanto, é necessário frisar que o fato de o princípio do contraditório haver limitações não o torna irrelevante, pelo contrário, este contemporaneamente vem tomando mais força, podendo atuar agora em duas dimensões: o contraditório formal e o substancial. O primeiro diz respeito ao direito de participação, comunicação, ciência das partes e à dualidade na audiência dentro do litígio, direitos básicos e convencionais. Já o segundo possui uma profundidade maior, indicando um poder de influência das partes no processo e, consequentemente, no provimento judicial (DIDIER, 2008).

Acerca do poder de influência, adquirido no contraditório substancial, Didier (2008) ensina:

Se não for conferida a possibilidade de a parte influenciar a decisão do magistrado - isso é poder de influência, poder de interferir na decisão do magistrado, interferir nos argumentos, interferir com ideias, com fatos novos, com argumentos jurídicos novos; se ela não puder fazer isso, a garantia do contraditório estará ferida.

Assim, tal poder de influência evitará que as partes sejam surpreendidas dentro do processo por decisão fundamentada em fatos e direitos estranhos ao litígio, ou que não tenha sido Ihes oportunizada manifestação.

\section{VEDAÇÃO À DECISÃO SURPRESA}

Delineada a relevância do princípio do contraditório dentro do direito, faz-se necessário estudar o princípio de vedação às decisões surpresa.

Inicialmente, quanto à decisão surpresa, Souza (2014) a define como:

[...] uma decisão fundada em premissas que não foram objeto de prévio debate ou a respeito das quais não se tomou prévio conhecimento no processo em que é proferida. Ou seja, a decisão surpresa é aquela cujos 
fundamentos não foram mencionados no processo ou a respeito dos quais não foi conferida a oportunidade de prévia manifestação. É uma decisão que surpreende a todos porque é pronunciada sem que ninguém exceto seu prolator tenha tido oportunidade de tomar conhecimento prévio sobre seus fundamentos. Por outras palavras, trata-se de uma decisão sobre a qual não se oferece previamente a chance de conhecimento ou manifestação acerca de seus fundamentos. Tais premissas sobre as quais está fundada a decisão surpresa podem ser questões de fato ou de direito, a respeito das quais não se tomou conhecimento, ou melhor, não foram ventiladas no processo para possibilitar o debate à luz do contraditório.

Nesta esteira, o princípio de vedação à decisão surpresa é utilizado para evitar que o Judiciário ultrapasse os limites do litígio, decidindo de maneira diversa dos pedidos, ou fundamentando em tese não ventilada ao longo do processo, o que acarreta em grande prejuízo às partes, não thes sendo conferidas oportunidade de manifestação acerca do fundamento utilizado.

O princípio em comento possui natureza constitucional, tendo em vista que deriva do princípio do contraditório, tipificado na Carta Magna. Neste princípio, o juiz possui o "dever constitucional de não pronunciar decisão que contenha matéria de fato ou de direito que não tenha sido previamente submetida à manifestação das partes" (SANTOS, 2018).

Dentre as novidades do Código de Processo Civil, encontra-se a positivação do princípio da vedação de decisão surpresa. O referido princípio deriva das garantias constitucionais do Contraditório e do Devido Processo Legal, os quais são de suma relevância no ordenamento jurídico brasileiro. $\mathrm{O}$ artigo 10 do Código de Processo Civil trouxe o princípio da Vedação de Decisão Surpresa, nos seguintes termos: "O juiz não pode decidir, em grau algum de jurisdição, com base em fundamento a respeito do qual não se tenha dado às partes oportunidade de se manifestar, ainda que se trate de matéria sobre a qual deva decidir de ofício" (BRASIL, 2015).

A referida disposição legal proíbe que o juiz decida sobre qualquer questão que não tenha sido oportunizada às partes manifestação dentro do processo, inclusive sobre questões que possam ser conhecidas de ofício pelo magistrado (de ordem pública). Cumpre salientar que há diferença entre o juiz poder agir sem a provocação das partes e sem ouvi-las. A dispensa da provocação não dispensa o contraditório (CABRAL; CRAMER, 2016).

Diante disso, o fato de poder declarar uma matéria de ofício não obsta que, da mesma forma, o magistrado precisará ouvir as partes antes de decidir, não 
significando a necessidade de requerimento das partes, mas oportunizando a manifestação das partes. Santos (2018) exemplifica a aplicação do princípio da vedação de decisão surpresa em um caso em que o juiz, ao se deparar com um texto normativo que the parece inconstitucional, deve intimar as partes para que estas manifestem-se acerca da constitucionalidade ou não da norma antes de afastar sua incidência.

É indubitável que o Princípio da Vedação de Decisão Surpresa possui papel fundamental no processo civil atual, tanto que fora positivado no diploma processual civil, sendo que em caso de inobservância pode acarretar em anulação da decisão que surpreendeu as partes, visto tratar-se de norma processual que não pode ser violada. Nesta situação, o Tribunal superior, reconhecendo a violação ao princípio estudado, anulará a decisão emanada em primeiro grau.

O Código de Processo Civil atual traz ainda como norma fundamental o artigo 6": "Todos os sujeitos do processo devem cooperar entre si para que se obtenha, em tempo razoável, decisão de mérito justa e efetiva", ou seja, as partes do processo devem cooperar pedindo, alegando e provando, visando a boa-fé do artigo $5^{\circ}$ do Código de Processo Civil, o qual preconiza: "Aquele que de qualquer forma participa do processo deve comportar-se de acordo com a boa-fé", devendo o juiz exercer seu poder resguardados os princípios do contraditório e da ampla defesa. A fim de corroborar com o delineado, o artigo $9^{\circ}$ do CPC é claro no sentido de que "Não se proferirá decisão contra uma das partes sem que ela seja previamente ouvida."

Assim, não apenas as partes devem promover a boa-fé, o contraditório e a cooperação, sendo necessário que o juiz atuante, do mesmo modo, obedeça a tais fundamentos. Donizetti (2018) afirma que o dever de cooperação entre os sujeitos do processo tem o intuito de afastar o individualismo do processo, trazendo diálogo entre as partes e o Estado, e não necessariamente um embate. Entretanto, existem limites a esta regra de cooperação dentro do processo. O juiz possui limites a sua atuação de cooperação, não devendo nunca sair de seu papel imparcial. Ao advogado, por sua vez, o limite é estabelecido ao seu papel de defesa ao seu cliente, sendo que o dever de cooperação nunca poderá prejudicar o direito de defesa da parte. $O$ autor ainda elenca cinco deveres das partes e do magistrado na prática da cooperação forense, quais sejam: dever de esclarecimento, dever de consulta, dever de prevenção, dever de auxílio e dever de correção e urbanidade. 
O primeiro diz respeito ao esclarecimento de alegações, pedidos ou posições do juízo. O segundo, por sua vez, está intimamente ligado ao contraditório e o princípio da vedação à decisão surpresa, já que obriga ao juiz intimar as partes para manifestações acerca de fatos ou de direito. O dever de prevenção, que é o terceiro, diz respeito ao dever de o juiz intimar a parte para sanar defeitos processuais. Quanto ao dever de auxílio, este elenca que a "obrigação do juiz de auxiliar a parte a superar eventual dificuldade que the tolha o exercício de seus ônus ou deveres processuais". Por fim, a correção e urbanidade fala acerca do dever de todos agirem com boa-fé, com conduta ética, adequada e respeitosa dentro do litígio (DONIZETTI, 2018).

Em caso de não observância de tais deveres, e portanto, desrespeitando os princípios em questão, a decisão acarretará em nulidade, já que "o ato praticado, concretamente, é típico ou perfeito quando se amolda exatamente ao padrão da lei; é atípico ou defeituoso, quando dele se afasta" (THEODORO JUNIOR, 1999).

Nery Junior (2010) assevera que se o juiz decidir de ofício sobre questão de ordem pública não submetida anteriormente às partes para manifestação, tal decisão será nula por violação ao contraditório já que uma das partes estará sendo prejudicada e outra beneficiada com a decisão surpresa, ofendendo a "paridade das armas", tornando a decisão nula. Tal nulidade poderá ser suscitada por meio de recursos.

Quando proferidas decisões surpresas, na ausência de prejuízo às partes e cumprida sua finalidade, não há o que se falar de suscitação de nulidade. Ainda, a parte beneficiada não poderá de forma alguma pleitear o reconhecimento da nulidade, sob pena de ferir o disposto nos artigos 276 e 282, $\S 2^{\circ}$ do Código de Processo Civil, que dispõem (SANTOS, 2018):

Art. 276 - Quando a lei prescrever determinada forma sob pena de nulidade, a decretação desta não pode ser requerida pela parte que lhe deu causa.

Art. 282, $\S 2^{\circ}-$ Quando puder decidir o mérito a favor da parte a quem aproveite a decretação da nulidade, o juiz não a pronunciará nem mandará repetir $o$ ato ou suprir-Ihe a falta.

Entretanto, é necessário ter em mente que, apesar do magistrado desrespeitar o princípio da vedação surpresa e, consequentemente gerar nulidade no processo, tal nulidade não será insanável, tendo em vista tratar-se de defeito procedimental e, "por 
mais grave que seja, mesmo que apto a gerar a invalidade do procedimento ou de um dos seus atos, todo defeito é sanável" (DIDIER; NOGUEIRA, 2011).

Assim, o princípio do contraditório, alinhado e aliado ao princípio da vedação à decisão surpresa, evitam a prolação de decisão surpresa e a decorrente decretação de nulidade.

\title{
4 RELAÇÃO E APLICABILIDADE DOS PRINCÍPIOS DO CONTRADITÓRIO E DA VEDAÇÃO À DECISÃO SURPRESA NO CÓDIGO DE PROCESSO CIVL E NA JURISPRUDÊNCIA CATARINENSE
}

Dando prosseguimento ao até então exposto, tem-se que a melhor maneira de garantir um procedimento adequado ao longo do processo, viabilizando o princípio do contraditório, é a comunicação entre o juiz e as partes, para que as mesmas possam participar efetivamente do processo com chances de se manifestarem a fim de atingir o resultado esperado. A este ponto, transcreve Didier Júnior, Braga e Oliveira (2015):

\begin{abstract}
O principal fundamento da comparticipação é o contraditório como garantia de influência e não surpresa. [...] Nesse sentido, o princípio do contraditório receberia uma nova significação, passando a ser entendido como direito de participação na construção do provimento, sob a forma de uma garantia processual de influência e não surpresa para a formação das decisões. [...].
\end{abstract}

Com base nisso, vê-se que o princípio da vedação de decisão surpresa não está relacionado às partes saberem o que de fato será decidido no decorrer no processo como um todo, mas sim, à possibilidade delas tomarem conhecimento acerca dos possíveis fundamentos da decisão, a fim de que possam defender seus direitos de maneira genuína, sejam eles de matéria de fato ou de direito.

Assim, o princípio do contraditório é visto como o direito de a parte participar da construção das normas jurídicas individualizadas (dispositivo da decisão) e gerais (tese da fundamentação), ou seja, participando de forma efetiva na construção de cada decisão dentro do litígio (DIDIER JUNIOR; BRAGA; OLIVEIRA, 2015).

Dentro do processo civil brasileiro, os princípios do contraditório e da vedação à decisão surpresa atuam de maneira evidente. Santos Júnior (2018) destaca a aplicabilidade de tais fundamentos no Código de Processo Civil de 2015 dentro de quatorze assuntos que podem ser objeto das decisões de um magistrado, sendo 
estes: indeferimento e emenda da petição inicial; improcedência liminar do pedido; reconhecimento liminar e no curso do processo de prescrição e de decadência; adaptabilidade do procedimento pelo juiz; condenação nas sanções processuais por litigância de má-fé e por ato atentatório à dignidade da justiça; impugnação ou réplica às defesas do réu; inversão do ônus da prova no Código de Defesa do Consumidor e distribuição dinâmica do ônus da prova; juntada de prova documental; conhecimento de fato e direito superveniente na fase de conhecimento; conhecimento de fato $\mathrm{e}$ direito superveniente em grau recursal; inadmissibilidade dos recursos; julgamento monocrático dos recursos: provimento e improvimento; julgamento dos embargos de declaração com efeito modificativo; julgamento com fundamento em precedentes judiciais, explica-se.

Como exemplo, tem-se que o artigo 319 do Código de Processo Civil prevê os requisitos para a petição inicial, sendo que, em caso de não observância, o juiz deverá mandar emendá-la. Uma decisão indeferindo a petição inicial, sem oportunizar a emenda à parte, é considerada surpresa (SANTOS JÚNIOR, 2018).

Assim ocorre também com os demais institutos mencionados. Não sendo caso de limitação ao contraditório, ou seja, não sendo inútil, postecipado ou eventual, deve ser oportunizada a manifestação às partes acerca de tais matérias, sob pena de ferimento não só ao princípio constitucional do contraditório, como também do princípio que deriva deste, o da vedação às decisões surpresas.

As garantias ora estudadas possuem um único e claro objetivo: trazer segurança jurídica às partes litigantes. Acerca do tema Marinoni, Arenhart e Mitidiero (2015) lecionam:

\footnotetext{
Essa seleção, dimensionada a partir das manifestações das partes e eventualmente por indicações do juiz (Hinweispjlicht), cria a expectativa legítima para as partes de que a decisão será fundamentada dentro da moldura delineada pelo debate processual. Essa expectativa legítima constitui manifestação do direito à segurança jurídica no processo e veda a prolação de decisões-surpresas no processo (Verbot der Uberraschungsentscheidungen).
}

A necessidade de o Judiciário estabelecer segurança jurídica em suas decisões atinge muito além do que as partes do processo judicial em que houve o pronunciamento. É claro que as partes serão, de uma maneira objetiva, atingidas com maior intensidade, já que o processo tem por objeto algo de interesse dos litigantes. 
Ocorre que, de uma maneira mais ampla, a utilização do princípio da vedação à decisão surpresa trará maior credibilidade ao próprio Órgão perante a sociedade, atingindo o interesse público, e possibilitando à população bons olhares à administração pública da justiça (TUCCI et al., 2019).

Assim, delineada a utilização dos princípios em destaque neste assunto dentro do processo civil brasileiro, faz-se necessária a demonstração dentro da jurisprudência. Para tanto, comenta-se julgado do Tribunal de Justiça de Santa Catarina.

Em sede de recurso de apelação, com autos número 030045410.2014.8.24.0068, do município de Seara, o Tribunal julgou procedente recurso que se destinava a cassar a sentença de um juiz do primeiro grau, isso porque, como sustentou a apelante, o magistrado baseou-se em matéria que não havia sido discutida dentro do processo, ferindo o contraditório e proferindo sentença baseada em fatos que surpreenderam as partes.

Para entender o caso, descreve-se breve relato.

A autora ajuizou ação para reaver indenização de uma seguradora em virtude da invalidez funcional, total e permanente por doença que a acomete. A apólice fora contratada em grupo. Na defesa, a ré alegou a ausência de requerimento administrativo ulterior ao pedido judicial, bem como que a apólice não cobria o evento incapacitante, e ainda a inexistência de invalidez da autora.

$\mathrm{Na}$ fase de instrução processual, ainda no primeiro grau, foram produzidas as provas. Dentre estas, fora elaborado um laudo pericial, sendo constatado que a doença da autora era anterior à contratação da apólice. Assim, com base nesta informação, o magistrado decidiu em desfavor da autora, indeferindo o pedido inicial com base neste argumento, sem ao menos oportunizar às partes manifestação acerca da prova, ou ainda, ter sido esta uma tese arguida pelos envolvidos no litígio.

Conforme verifica-se da decisão do Tribunal de Justiça, o magistrado de primeiro grau feriu os princípios do contraditório e da vedação à decisão surpresa, tendo baseado sua decisão em matéria que não fora suscitada ao longo do processo por nenhuma das partes. Foi este o entendimento adotado pelo Colegiado, conforme colhe-se do julgado: 
[...] pode-se concluir que o juízo feriu o contraditório em sua dimensão substancial, qual seja, no direito das partes de influenciar na conclusão do julgador. [...] Assim, ao julgar o feito utilizando-se de fundamento inédito, o juízo limitou a manifestação e defesa das partes sobre essa questão, gerando a nulidade da sentença, por ofensa ao princípio da vedação a decisões surpresas (SANTA CATARINA, 2014).

Assim, o Tribunal julgou procedente o pedido da apelante, cassando a sentença de primeiro grau, e, reafirmando a necessidade de ser oportunizada às partes o contraditório acerca do fundamento utilizado pelo juiz, qual seja o surgimento de doença após a contratação da apólice.

Diante disso, demonstra-se a aplicabilidade do tema em enfoque neste estudo dentro da rotina jurisprudencial, sendo corriqueiros pronunciamentos dos Tribunais cassando decisões prolatadas de maneira arbitrária pelos magistrados, o que demonstra a existência de desrespeito ao princípio do contraditório e da vedação à decisão surpresa, mas a esperança de revisão e anulação de provimentos fundamentados em matéria não discutida dentro do litígio.

\section{CONSIDERAÇÕES FINAIS}

Os princípios do contraditório e da vedação a decisão surpresa são de suma importância, estando previstos no Código de Processo Civil. O princípio do contraditório é uma garantia constitucional de conhecimento da demanda e dos atos processuais, também é uma garantia de influência e participação na construção da decisão judicial. O Código de Processo civil de 2015 adotou a acepção material do contraditório onde faz-se necessário que a parte tenha conhecimento e possa se manifestar no processo, além disso que possa influenciar na decisão do juiz.

Além disso, o princípio do contraditório é um dos principais fundamentos do Estado Democrático de Direito. No Brasil, ele é uma garantia positivada na Constituição Federal, trazendo maior credibilidade e abrangência dentro do ordenamento jurídico.

Por muito tempo o contraditório limitou-se à mera ciência das partes acerca de matérias suscitadas ao longo do litígio. Ocorre que, atualmente o princípio do contraditório ganhou maior notoriedade, sendo ampliada a sua dimensão para que as 
partes possuam o poder de influência dentro do processo e, consequentemente, no provimento do magistrado. Tal amplitude denomina-se de contraditório substancial.

O contraditório substancial impõe ao magistrado o dever de cooperar com as partes, informando a constatação de qualquer matéria dentro do processo, ainda que de ordem pública, a fim de evitar a emissão de decisões que surpreendam as partes.

Nesta senda, o princípio da vedação à decisão surpresa deriva do princípio constitucional do contraditório, agindo de forma a impedir os magistrados de fundamentarem suas decisões em matérias não ventiladas ao longo do processo, e não oportunizada a manifestação das partes.

O magistrado que não observa tais princípios estará sujeito a ter sua decisão anulada, diante da violação. Entretanto, para que a parte tenha a possibilidade de suscitar tal nulidade é necessário que seja demonstrado o interesse e o prejuízo em assim pleitear por meio do recurso adequado.

Neste ínterim, é fundamental destacar a relevância do contraditório substancial no combate às decisões temerárias, que, por vezes, acarretam em recursos que poderiam ser evitados, tornando, assim, o processo moroso.

Dentro do Código de Processo Civil, como restou delineado ao longo deste estudo, ambos os princípios estão positivados, sendo obrigatória a observância destes pelo Judiciário.

A jurisprudência vem, cada vez mais, identificando decisões surpresas e realizando a aplicação dos princípios em comento, a fim de oportunizar aos sujeitos do processo segurança jurídica, assegurando que não haverá decisão baseada em matéria não arguida e debatida.

Diante disso, quando exercido o poder de influência das partes dentro da dimensão do contraditório substancial, os litigantes poderão participar da construção do provimento final, afastando, deste modo, a prolação de decisões surpresas.

Tal fato contribui para que a sociedade obtenha, cada vez mais, segurança na justiça brasileira, retirando do juiz a visão de poder absoluto e demonstrando que, caso o magistrado não observe a lei e o que está sendo discutido na lide, sua decisão estará sujeita à revisão. 


\section{REFERÊNCIAS}

BRASIL. Constituição (1988). Constituição Federal da República Federativa do Brasil. Disponível em: <http://www.planalto.gov.br/ccivil_03/constituicao/ constitui\%C3\%A7ao.htm>. Acesso em: 12 maio 2020.

BRASIL. Lei n. 13.105, de 16 de maio de 2015. Código de Processo Civil. Disponível em: <http://www.planalto.gov.br/ccivil_03/_ato20152018/2015/lei//13105.htm> Acesso em: 12 maio 2020.

CABRAL, Antonio do Passo. Nulidades no processo moderno. 2ed. Rio de Janeiro: Forense, 2010.

CABRAL, Antonio do Passo; CRAMER, Ronaldo. Comentários ao novo código de processo civil. 2.ed. Rio de Janeiro: Forense, 2016.

DIDIER JUNIOR; Fredie; BRAGA, Paula Sarno; OLIVEIRA, Rafael Alexandria de. Curso de direito processual civil: teoria da prova, direito probatório, ações probatórias, decisão, precedente, coisa julgada e antecipação dos efeitos da tutela. 10. ed. Salvador: Ed. Jus Podivim, 2015.

DIDIER JUNIOR, Fredie; NOGUEIRA, Pedro Henrique Pedrosa. Teoria dos fatos jurídicos processuais. Salvador: JusPodivm, 2011.

DONIZETTI, Elpídio. Novo Código de Processo Civil Comentado. 3.ed. São Paulo: Atlas, 2018.

MORAES, Alexandre. Direito Constitucional. 13.ed. São Paulo: Atlas, 2003.

MARINONI, Luiz Guilherme; ARENHART, Sérgio Cruz; MITIDIERO, Daniel. Curso de Processo Civil. São Paulo: Revista dos Tribunais, 2015.

NERY JUNIOR, Nelson. Princípios do processo na Constituição Federal: civil penal e administrativo. 9. ed. São Paulo: Revista dos Tribunais, 2010.

SANTA CATARINA, Tribunal de Justiça. Apelação Cível n. 0300464-

10.2014.8.24.0068. Relator: Desembargador Helio David Vieira Figueira dos Santos. Florianópolis, 27 fev. 2020. Disponível em: <http://busca.tjsc.jus.br/jurisprudencia/ \#resultado_ancora>. Acesso em: 30 out. 2020.

SANTOS JÚNIOR, Sândalo Vianna. A relação entre o contraditório e a fundamentação das decisões no processo civil do estado democrático de direito. Espírito Santo, 2013.

SANTOS, Welder Queiroz dos. Princípio do contraditório e vedação de decisão surpresa. Rio de Janeiro: Forense, 2018. 
SOUZA, André Pagani de. Vedação das decisões-surpresa no processo civil. São Paulo: Saraiva, 2014.

THEODORO JÚNIOR, Humberto et al. Novo CPC: fundamentos e sistematização. Rio de Janeiro: Forense, 2015.

THEODORO JUNIOR, Humberto. Nulidades no Código de Processo Civil. Revista Síntese e direito civil e processual civil. Curitiba, a. 1, n. 1, set./out. 1999.

TUCCI, José Rogério Cruz et al. Código de processo civil anotado. AASP. Digital. 2019. Disponível em: <https://aaspsite.blob.core.windows.net/aaspsite/ 2019/02/CPC_anotado25.2.2019_atual.pdf>. Acesso em: 2 nov. 2020.

Artigo recebido em: 17/11/2020

Artigo aceito em: 10/12/2020

Artigo publicado em: 29/07/2021 